\title{
Sex differences in mortality in patients
} with COPD

\author{
J.P. de Torres*,\#, ${ }^{\star}$, C.G. Cote ${ }^{\uparrow, \uparrow}$, M.V. López ${ }^{+}$, C. Casanova\# ${ }^{\#}$ O. Díaz ${ }^{\S}$, \\ J.M. Marin ${ }^{f}$, V. Pinto-Plata**, M.M. de Oca ${ }^{\# \#, ~ H . ~ N e k a c h `, ~ L . J . ~ D o r d e l l y ~}$ \\ A. Aguirre-Jaime ${ }^{\#}$ and B.R. Celli**
}

ABSTRACT: Little is known about survival and clinical prognostic factors in females with chronic obstructive pulmonary disease (COPD). The aim of the present study was to determine the survival difference between males and females with COPD and to compare the value of the different prognostic factors for the disease.

In total, 265 females and 272 males with COPD matched at baseline by BODE (body mass index, airflow obstruction, dyspnoea, exercise capacity) and American Thoracic Society/European Respiratory Society/Global Initiative of Chronic Obstructive Lung Disease criteria were prospectively followed. Demographics, lung function, St George's Respiratory Questionnaire, BODE index, the components of the BODE index and comorbidity were determined. Survival was documented and sex differences were determined using Kaplan-Meier analysis. The strength of the association of the studied variables with mortality was determined using multivariate and receiver operating curves analysis.

All-cause (40 versus 18\%) and respiratory mortality (24 versus $10 \%$ ) were higher in males than females. Multivariate analysis identified the BODE index in females and the BODE index and Charlson comorbidity score in males as the best predictors of mortality. The area under the curve of the BODE index was a better predictor of mortality than the forced expiratory volume in one second for both sexes.

At similar chronic obstructive pulmonary disease severity by BODE index and forced expiratory volume in one second, females have significantly better survival than males. For both sexes the BODE index is a better predictor of survival than the forced expiratory volume in one second.

KEYWORDS: BODE (body mass index, airflow obstruction, dyspnoea, exercise capacity) index, chronic obstructive pulmonary disease, mortality, sex

$\mathbf{T}$ here is increasing evidence supporting sex differences in the clinical expression of chronic obstructive pulmonary disease (COPD). Females seem to be more susceptible to the toxic effects of tobacco than males [1-5], They also report more anxiety and depression [6, 7], worse symptoms [8-10], lower exercise capacity [11], more airway hyperresponsiveness [12] and worse health-related quality of life (HRQoL) $[8,11,13,14]$ than males. In a recent study by MARTINEZ et al. [8], females with severe emphysema enrolling in the National Emphysema Treatment Trial, smoked less, had a worse modified BODE (body mass index, airflow obstruction, dyspnoea, exercise capacity) index and lower diffusing capacity of the lung for carbon monoxide than their male counterparts. The pathological lung specimens of females exhibited smaller airway lumens with disproportionately thicker airway walls, less extensive emphysema characterised by smaller hole size and less peripheral involvement than those of males. The same results were also produced by DRANSFIELD et al. [15].

Whether or not the clinical differences in the expression of COPD in females result in different all-cause and respiratory mortality compared to those of males remains unknown. The limited available information about sex differences in COPD mortality is derived from studies of patients with advanced stages of disease and hypoxaemic respiratory insufficiency [16-19].

In the present study, the authors tested the hypothesis that females with similar degrees of COPD severity (determined by the BODE index and percentage forced expiratory volume in one second $(\mathrm{FEV} 1 \%)$ ) have a different survival than males in a cohort of COPD patients with a wide range of airway obstruction from five countries
AFFILIATIONS

*Clínica Universitaria de Navarra, Pamplona,

${ }^{\#}$ Hospital Universitario Nuestra Señora de la Candelaria,

Tenerife, and

${ }^{f}$ Hospital Miguel Servet,

Zaragoza, Spain.

'Bay Pines Veterans Affairs Health

Care System, Bay Pines, FL, and

${ }^{\star *}$ Caritas St Elizabeth's Medical

Center, Tufts University,

Boston, MA, USA

+Universidad de la República,

Montevideo, Uruguay.

${ }^{\text {s} D e p a r t a m e n t o ~ d e ~ E n f e r m e d a d e s ~}$

Respiratorias, Pontificia Universidad

Católica de Chile, Santiago, Chile.

\#\# Hospital Universitario de Caracas,

Caracas, Venezuela.

"Both authors contributed equally to

this manuscript.

CORRESPONDENCE

J.P. de Torres

Pulmonary Dept,

Clínica Universitaria de Navarra,

Av. Pío XII 36,

Pamplona,

31008,

Spain

Fax: 34948296500

E-mail: jupa65@hotmail.com

Received:

June 252008

Accepted after revision:

October 142008

STATEMENT OF INTEREST

None declared. 
(USA, Spain, Chile, Venezuela and Uruguay). In addition, the strength of the association between the baseline variables and mortality in the two sexes was also tested.

\section{METHODS}

\section{Patients}

In total, 265 females with a wide range of COPD severity, according to the American Thoracic Society (ATS), European Respiratory Society (ERS) [20] and the Global Initiative for Chronic Obstructive Lung Disease (GOLD) criteria [21], were sequentially recruited into the BODE observational study between January 1997 and September 2006, at several clinics in the USA (Boston, MA and Bay Pines, FL), Venezuela, Chile, Uruguay and Spain (Tenerife, Pamplona and Zaragoza). As originally described, the BODE study [22] prospectively enrolled a cohort of well phenotyped patients with COPD irrespective of sex. Initially, few females were enrolled but over time more participated. Once an appropriate number of female patients followed for $\geqslant 1 \mathrm{yr}$ had been achieved, the current authors decided to retrospectively analyse the presence of sex differences in outcome. A total of 272 males from the same BODE cohort were matched by region and similar stage of COPD severity by BODE and ATS/ERS/GOLD criteria. Special attention was given to include individuals enrolled during the same study period to avoid treatment differences over time. For example, if a female COPD patient was enrolled in June 2000, a male COPD patient with similar FEV1\% and BODE index enrolled during the same year and region was selected for the matching process. The matched patients were obtained from an initial sample of 1,115 males and 269 females with COPD. Every female could be matched with a male with an FEV 1 of $\pm 5 \%$ predicted and similar BODE index. To avoid selection bias, when more than one male was matched and

TABLE 1 Baseline characteristics of patients in the cohort

\begin{tabular}{|c|c|c|c|}
\hline Variables & Male & Female & p-value ${ }^{\#}$ \\
\hline Subjects $n$ & 272 & 265 & \\
\hline Age yrs & $67 \pm 8$ & $63 \pm 10$ & $<0.001$ \\
\hline Current smoking \% & 32 & 44 & 0.005 \\
\hline Tobacco use pack $\cdot \mathrm{yr}^{-1}$ & $81 \pm 43$ & $51 \pm 29$ & $<0.001$ \\
\hline Charlson's index points & $3.8 \pm 2.6$ & $2.7 \pm 2.4$ & $<0.001$ \\
\hline BODE index points & $3.49 \pm 2.5$ & $3.37 \pm 2.1$ & 0.55 \\
\hline MMRC points & $2.0 \pm 1.1$ & $2.11 \pm 0.9$ & 0.5 \\
\hline 6MWD m & $392 \pm 138$ & $392 \pm 103$ & 0.9 \\
\hline BMI $\mathbf{k g} \cdot \mathrm{m}^{-2}$ & $26.8 \pm 5$ & $25.7 \pm 5$ & $<0.01$ \\
\hline FEV 1 \% pred & $49 \pm 20$ & $50 \pm 19$ & 0.87 \\
\hline FVC \% pred & $74 \pm 22$ & $78.7 \pm 23$ & 0.05 \\
\hline FEV $1 / F V C \%$ & $46 \pm 13$ & $48.8 \pm 12$ & 0.06 \\
\hline IC/TLC \% & $32 \pm 1$ & $30 \pm 1$ & 0.05 \\
\hline SGRQ total & $44 \pm 21$ & $48 \pm 19$ & 0.04 \\
\hline
\end{tabular}

Data are presented as mean $\pm \mathrm{SD}$, unless otherwise stated. BODE: body mass index (BMI), airflow obstruction, dyspnoea, exercise capacity; MMRC: modified Medical Research Council dyspnoea scale; 6MWD: 6-min walk distance; FEV1: forced expiratory volume in one second; \% pred: \% predicted; FVC: forced vital capacity; IC: inspiratory capacity; TLC: total lung capacity; SGRQ: St George's Respiratory Questionnaire. *: comparison between males and females. they had a different BODE index, the present authors decided to include both male patients with the same FEV1; this event occurred in seven patients. The four female patients who had no match were not included in the analysis. Inclusion and exclusion of these 11 patients do not affect the results. Participants were receiving standard medical treatment according to the ATS/ERS consensus [20]. The human research-review board at each site approved the study and all patients signed the informed consent. The inclusion/exclusion criteria have been previously published [22]. Briefly, COPD was defined by a history of smoking $\geqslant 10$ pack-yrs and a FEV1/forced vital capacity ratio $<0.7$ measured $20 \mathrm{~min}$ after the administration of $400 \mu \mathrm{g}$ of inhaled albuterol. Patients were excluded if they had a history of asthma, bronchiectasis, tuberculosis or other confounding diseases, such as congestive heart failure, obliterative bronchiolitis or diffuse panbronchiolitis. The patients completed evaluation within 6 weeks of enrolment and continued to be followed thereafter until August 2007 or until death. The patient and their family were contacted if the patient failed to return for appointments. Death from any cause and from specific respiratory causes was recorded. The investigators at each site determined the cause of death after reviewing the medical record and death certificate. The cause of death was classified as respiratory (if it was due to COPD, respiratory failure or respiratory tract infection), cardiovascular, lung cancer or others.

\section{Measurements}

Demographic and anthropometric information was collected. Spirometry, lung volumes and the 6-min walking distance (6MWD) were performed following ATS guidelines [23, 24]

\section{TABLE 2 Baseline characteristics of male and female patients who died from any cause during the study period}

\begin{tabular}{lccc} 
Variables & Male & Female & p-value $^{\#}$ \\
\hline Subjects n & 97 & 44 & \\
Age yrs & $70 \pm 8$ & $68 \pm 8$ & 0.19 \\
Current smoking \% & 30 & 35 & 0.64 \\
Tobacco use pack·yr ${ }^{-1}$ & $90 \pm 38$ & $70 \pm 40$ & $<0.001$ \\
Charlson's index points & $4.75 \pm 2.9$ & $3.8 \pm 2.6$ & 0.08 \\
BODE index points & $4.9 \pm 2.6$ & $5 \pm 1.7$ & 0.69 \\
MMRC points & $2.64 \pm 0.9$ & $2.48 \pm 0.8$ & 0.34 \\
6MWD m & $305 \pm 135$ & $292 \pm 108$ & 0.58 \\
BMI kg $\cdot \mathbf{m}^{-2}$ & $26 \pm 5$ & $23.7 \pm 5$ & 0.03 \\
FEV $\%$ pred & $44 \pm 19$ & $39 \pm 14$ & 0.16 \\
FVC \% pred & $67 \pm 19$ & $69 \pm 21$ & 0.61 \\
FEV 1 FVC \% & $44 \pm 13$ & $44 \pm 13$ & 0.99 \\
IC/TLC \% & $28 \pm 1$ & $27 \pm 1$ & 0.40 \\
SGRQ total & $52 \pm 19$ & $58 \pm 16$ & 0.11 \\
\hline
\end{tabular}

Data are presented as mean $\pm S D$, unless otherwise stated. BODE: body mass index (BMI), aifflow obstruction, dyspnoea, exercise capacity; MMRC: modified Medical Research Council dyspnoea scale; 6MWD: 6-min walk distance; FEV1: forced expiratory volume in one second; \% pred: \% predicted; FVC: forced vital capacity; IC: inspiratory capacity; TLC: total lung capacity; SGRQ: St George's Respiratory Questionnaire. " : comparison between males and females. 


\begin{tabular}{|c|c|c|c|c|}
\hline \multirow{2}{*}{$\begin{array}{l}\text { TABLE } 3 \\
\text { Variables }\end{array}$} & \multicolumn{4}{|c|}{$\begin{array}{l}\text { Baseline characteristics of male and female } \\
\text { patients who died from respiratory causes during } \\
\text { the study period }\end{array}$} \\
\hline & & Male & Female & p-value ${ }^{\#}$ \\
\hline \multicolumn{2}{|l|}{ Subjects $n$} & 55 & 21 & \\
\hline \multicolumn{2}{|l|}{ Age yrs } & $68 \pm 8$ & $67 \pm 9$ & 0.88 \\
\hline \multicolumn{2}{|c|}{ Current smoking \% } & 57 & 32 & 0.05 \\
\hline \multicolumn{2}{|c|}{ Tobacco use pack $\cdot \mathrm{yr}^{-1}$} & $86 \pm 41$ & $69 \pm 40$ & 0.86 \\
\hline \multicolumn{2}{|c|}{ Charlson's index points } & $4.8 \pm 3$ & $4.0 \pm 2$ & 0.81 \\
\hline \multicolumn{2}{|c|}{ BODE index points } & $5.0 \pm 2.7$ & $5.1 \pm 1.7$ & 0.86 \\
\hline \multicolumn{2}{|c|}{ MMRC points } & $2.8 \pm 0.9$ & $2.5 \pm 0.8$ & 0.96 \\
\hline \multicolumn{2}{|l|}{ 6MWD m } & $300 \pm 139$ & $285 \pm 115$ & 0.14 \\
\hline \multicolumn{2}{|l|}{ BMI $\mathrm{kg} \cdot \mathrm{m}^{-2}$} & $26 \pm 6$ & $23.5 \pm 5$ & 0.08 \\
\hline \multicolumn{2}{|l|}{ FEV $1 \%$ pred } & $42 \pm 18$ & $39 \pm 14$ & 0.08 \\
\hline \multicolumn{2}{|l|}{ FVC \% pred } & $73 \pm 23$ & $67 \pm 19$ & 0.93 \\
\hline \multicolumn{2}{|l|}{$\mathrm{FEV}_{1 / \mathrm{FVC}} \%$} & $43 \pm 13$ & $42 \pm 13$ & 0.86 \\
\hline \multicolumn{2}{|l|}{ IC/TLC \% } & $28 \pm 12$ & $27 \pm 9$ & 0.38 \\
\hline \multicolumn{2}{|l|}{ SGRQ total } & $55 \pm 21$ & $58 \pm 15$ & 0.47 \\
\hline \multicolumn{5}{|c|}{ 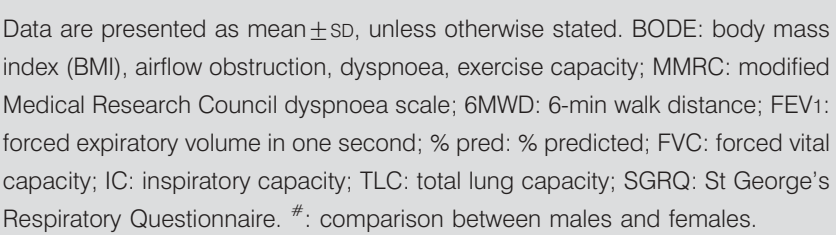 } \\
\hline
\end{tabular}

Dyspnoea was assessed using the modified Medical Research Council dyspnoea scale (MMRC) [25]. The body mass index (BMI) was calculated as the weight in $\mathrm{kg}$ divided by height in $\mathrm{m}^{2}$. The presence of comorbidities was evaluated using the Charlson scale [26], where points are assigned to the presence of different comorbidities. The score ranges from $0-37$, with the higher the score implying more comorbidities. Smoking status was expressed in pack-yrs. Inspiratory capacity (IC) was measured as previously described and IC/total lung capacity (TLC) was determined from the lung volume measurements [27]. The BODE index was measured and staged in quartiles as previously published [22]. In short, the BODE index is a multidimensional grading system integrated by four variables: BMI (B); airflow obstruction (O), as measured by the postbronchodilator FEV1 \% pred; dyspnoea (D), assessed by the MMRC score; and exercise tolerance (E) measured by 6MWD. The variables were graded from $0-3$ ( 0 or 1 for $\mathrm{BMI}$ ) and added to provide a total score ranging $0-10$. A higher score indicates a greater risk of death and one point increase in the index represents a $34 \%$ and $62 \%$ increase in global and respiratory mortality, respectively. The St George's Respiratory Questionnaire (SGRQ) was used to determine HRQoL [28] with the higher the index the greater health impairment and with four points representing a clinical significant difference [29].

\section{Statistical analysis}

Quantitative data with a normal distribution was presented as mean \pm SD. Qualitative data was described using relative frequencies. Survival times with all-cause and respiratory mortality were determined. Differences between female and male deceased patients were assessed using paired t-tests for
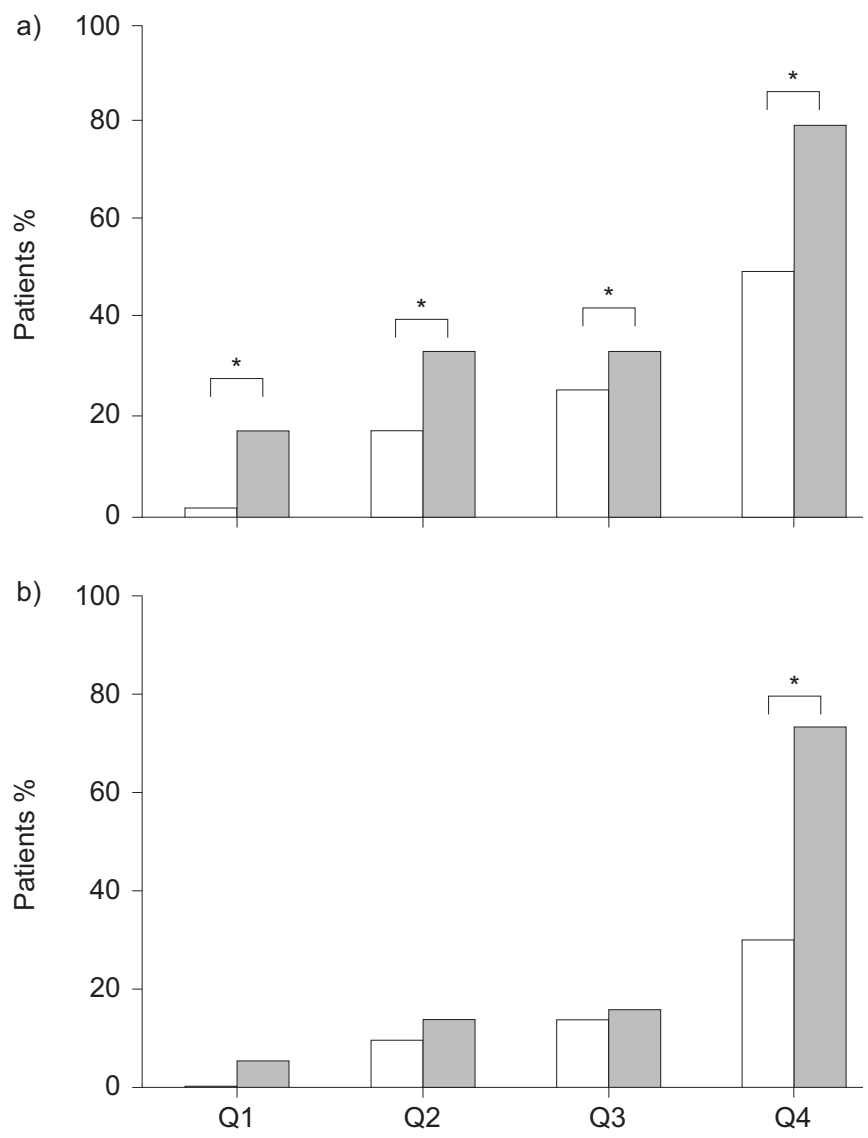

FIGURE 1. a) All-cause mortality and b) respiratory mortality represented by the four BODE (body mass index, airflow obstruction, dyspnoea, exercise capacity) quartiles. Significant differences were found in all quartiles for all-cause mortality and in Q4 for respiratory mortality. The number of female and male, respectively, allcause or respiratory mortality patients in each quartile was as follows. Q1: 85 and 97; Q2: 85 and 90; Q3: 56 and 46; Q4: 39 and 39. $\square$ : females; $\square$ : males. *: $p<0.05$

independent sample or Pearson Chi-squared test, depending on variable characteristics. Kaplan-Meier analysis was used for comparison survival between males and females with similar COPD severity (BODE index and FEV1\%). The statistical significance was evaluated using the log-rank test. Cox proportional hazard ratio analysis was performed to determine the best predictors of mortality in each sex, adjusting for factors that showed differences between males and females: age, pack-yrs, comorbidity and BMI. In the analysis all factors that have been shown to predict mortality in COPD patients were included: FEV1\%; 6MWD; MMRC; IC/TLC and the BODE index. To determine the relative predictive value for mortality of the BODE index compared with the $\mathrm{FEV} 1 \%$, C statistics were computed for a model containing FEV1 or the BODE score as the sole independent variable. In these analyses, the $\mathrm{C}$ statistic is a mathematical function of the sensitivity and specificity of the BODE index and FEV1\% in classifying patients by means of the Cox model as either dying or surviving. The null value for the $C$ statistic is 0.5 , with a maximum of 1.0; the higher the area under the curve, the better the predictive power. Significant levels for all tests were established as two-tailed p-value $\leqslant 0.05$. 


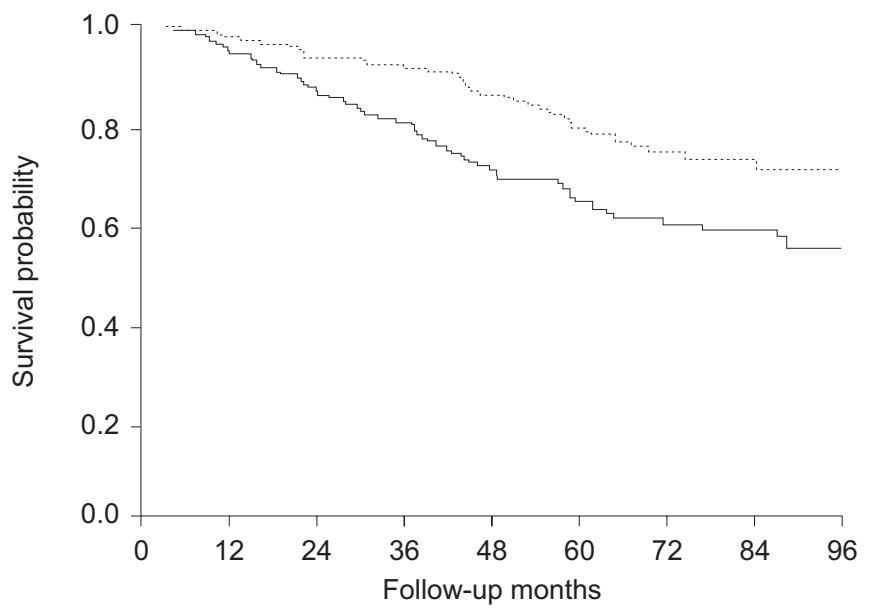

FIGURE 2. Kaplan-Meier survival curves of the study population by sex. Log rank analysis shows that survival is better for the female (83\%) than the male (67\%) population. ….... females; _—: males. The number of females at $0,12,24,36$, 48, 60, 72, 84 and 96 months follow-up were 265, 257, 249, 245, 237, 228, 232, 222 and 220, respectively. The number of males at 0, 12, 24, 36, 48, 60, 72, 84 and 96 months follow-up were 272, 257, 235, 221, 198, 191, 186, 185 and 183, respectively. Chi-squared: 19.3. Log rank analysis: $p<0.001$

\section{RESULTS}

The baseline characteristics of the study patients by sex are shown in table 1.

A similar number of males and females were recruited at all sites and there were no differences in any of the variables among regions (data not shown); therefore, the data is presented as a group. A total of 265 females and 272 males with COPD were included in the study. The patients were followed for a mean of $49 \pm 28$ months. FEV1\% ranged between 10 and $94 \%$ of predicted value. According to ATS/ERS/GOLD criteria, there were $14 \%$ COPD patients in stage I, $31 \%$ in stage II, $37 \%$ in stage III and $18 \%$ in stage IV. Conversely, $36 \%$ were in BODE Q1, 33\% in Q2, 19\% in Q3 and 12\% in Q4.

Table 1 shows that at similar degree of airflow obstruction, there were differences between males and females in age, smoking status, pack-yrs history, comorbidity, BMI and SGRQ.

\section{Mortality}

A total of 141 (26.2\%) patients died during the follow-up period. The mean follow-up time from enrolment to death was $34 \pm 21,39 \pm 22$ and $32 \pm 20$ months for the group, females and males, respectively. A total of 97 patients $(69 \%$ of the nonsurvivors) were male. In total, 76 (54\%) patients died due to respiratory causes during the study period. Mortality at each centre was higher in males than in females.

The characteristics of nonsurvivor male and female patients are shown in tables 2 and 3. For all-cause mortality, nonsurvivor females were very similar to males except for a lower BMI and lower tobacco consumption in pack-yrs. The BODE and the Charlson comorbidity indexes were similar in both sexes (table 2). Survivors and nonsurvivors were similar in all parameters for respiratory deaths (table 3).

Figure 1 shows all-cause and respiratory mortality in nonsurvivor males and females by BODE quartiles. Females had

\begin{tabular}{|c|c|c|c|c|}
\hline TABLE 4 & \multicolumn{4}{|c|}{$\begin{array}{l}\text { Cox proportional hazard ratio univariate analysis } \\
\text { to investigate the predictive power for mortality of } \\
\text { each of the selected variables in male and } \\
\text { female patients with chronic obstructive } \\
\text { pulmonary disease }\end{array}$} \\
\hline \multicolumn{2}{|c|}{ Outcome and variable } & HR & $95 \% \mathrm{Cl}$ & $\mathrm{p}$-value \\
\hline \multicolumn{5}{|c|}{ All-cause mortality } \\
\hline \multicolumn{5}{|l|}{ FEV $1 \%$} \\
\hline \multicolumn{2}{|l|}{ Males } & 0.98 & $0.97-0.99$ & 0.01 \\
\hline \multicolumn{2}{|l|}{ Females } & 0.93 & $0.90-0.97$ & $<0.001$ \\
\hline \multicolumn{5}{|l|}{ 6MWD } \\
\hline \multicolumn{2}{|l|}{ Males } & 0.99 & $0.98-0.99$ & $<0.001$ \\
\hline \multicolumn{2}{|l|}{ Females } & 0.99 & $0.98-0.99$ & $<0.001$ \\
\hline \multicolumn{5}{|l|}{ MMRC } \\
\hline \multicolumn{2}{|l|}{ Males } & 1.89 & $1.50-2.38$ & $<0.001$ \\
\hline \multicolumn{2}{|l|}{ Females } & 2.11 & $1.17-3.79$ & 0.01 \\
\hline \multicolumn{5}{|l|}{ IC/TLC } \\
\hline \multicolumn{2}{|l|}{ Males } & 0.01 & $0.002-0.20$ & 0.001 \\
\hline \multicolumn{2}{|l|}{ Females } & 0.91 & $0.83-0.99$ & 0.04 \\
\hline \multicolumn{5}{|l|}{ BODE } \\
\hline \multicolumn{2}{|l|}{ Males } & 1.30 & $1.27-1.46$ & $<0.001$ \\
\hline \multicolumn{2}{|l|}{ Females } & 1.65 & $1.31-2.07$ & $<0.001$ \\
\hline \multicolumn{5}{|c|}{ Respiratory mortality } \\
\hline \multicolumn{5}{|l|}{$\mathrm{FEV}_{1} \%$} \\
\hline \multicolumn{2}{|l|}{ Males } & 0.98 & $0.96-0.99$ & 0.01 \\
\hline \multicolumn{2}{|l|}{ Females } & 0.99 & $0.98-0.99$ & $<0.001$ \\
\hline \multicolumn{5}{|l|}{ 6MWD } \\
\hline \multicolumn{2}{|l|}{ Males } & 0.99 & $0.98-0.99$ & $<0.001$ \\
\hline \multicolumn{2}{|l|}{ Females } & 0.99 & $0.98-0.99$ & $<0.001$ \\
\hline \multicolumn{5}{|l|}{ MMRC } \\
\hline \multicolumn{2}{|l|}{ Males } & 2.24 & $1.68-2.97$ & $<0.001$ \\
\hline \multicolumn{2}{|l|}{ Females } & 2.48 & $1.32-4.68$ & 0.005 \\
\hline \multicolumn{5}{|l|}{ IC/TLC } \\
\hline Males & & 0.01 & $0.01-0.31$ & 0.006 \\
\hline Females & & 0.01 & $0.00-0.77$ & 0.04 \\
\hline BODE & & & & \\
\hline Males & & 1.35 & $1.21-1.50$ & $<0.001$ \\
\hline Females & & 1.74 & $1.36-2.23$ & $<0.001$ \\
\hline
\end{tabular}

HR: hazard ratio; $\mathrm{Cl}$ : confidence interval; FEV1: forced expiratory volume in one second; 6MWD: 6-min walk distance; MMRC: modified Medical Research Council dyspnoea scale; IC: inspiratory capacity; TLC: total lung capacity; BODE: body mass index (BMI), airflow obstruction, dyspnoea, exercise

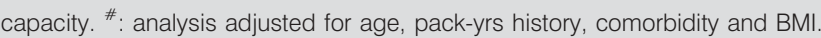

significantly lower all-cause mortality than males in all quartiles. Respiratory mortality was similar in all BODE quartiles except Q4 where it was higher in males.

The Kaplan-Meier analysis (fig. 2) showed that survival was significantly higher in females than males with similar BODE index and FEV1 $(\mathrm{p}<0.001)$.

\section{Univariate and multivariate analysis}

The predictive power for all-cause and respiratory mortality of the variables selected, adjusted for age, pack-yrs history, Charlson and BMI are shown in tables 4 and 5. Table 4 shows the results of the univariate analysis, whereas table 5 shows 


\begin{tabular}{lcccc} 
TABLE 5 & $\begin{array}{l}\text { Multivariate analysis including all variables } \\
\text { significant in the univariate analysis }\end{array}$ & \\
Outcome & Variable & HR & $\mathbf{9 5 \%} \mathbf{~ C l}$ & p-value \\
\hline All-cause mortality & & & & \\
$\quad$ Females & BODE & 2.26 & $1.6-3.2$ & $<0.001$ \\
Males & BODE & 1.4 & $1.21-1.61$ & $<0.001$ \\
& Charlson & 1.19 & $1.03-1.37$ & 0.032 \\
Respiratory mortality & & & & \\
Females & BODE & 3.17 & $1.87-5.36$ & $<0.001$ \\
Males & BODE & 1.53 & $1.30-1.79$ & $<0.001$ \\
\hline
\end{tabular}

HR: hazard ratio; Cl: confidence interval; BODE: body mass index (BMI), airflow

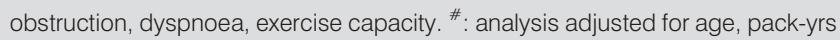
history, comorbidity and BMI.

the final result of the multivariate analysis, which included all factors that showed significance in the univariate analysis again adjusted for the same parameters. The BODE index was the only variable associated with all-cause mortality for females, whereas for males the model included the BODE index and Charlson comorbidity score. The model explained a higher percentage of the variance for females compared with males ( 32.5 versus $16.8 \%$; $<<0.001$ ). The BODE index was also the only variable associated with respiratory mortality for both sexes. This model explained a higher percentage of the variance $(46 \%)$ in females.

\section{Receiver operating curves analysis}

The discriminatory value of the BODE index in relation to survival was significantly higher than that of FEV1\% in both sexes (fig. 3).

\section{DISCUSSION}

The present study has two important findings. First, females with similar degrees of airflow obstruction and BODE index

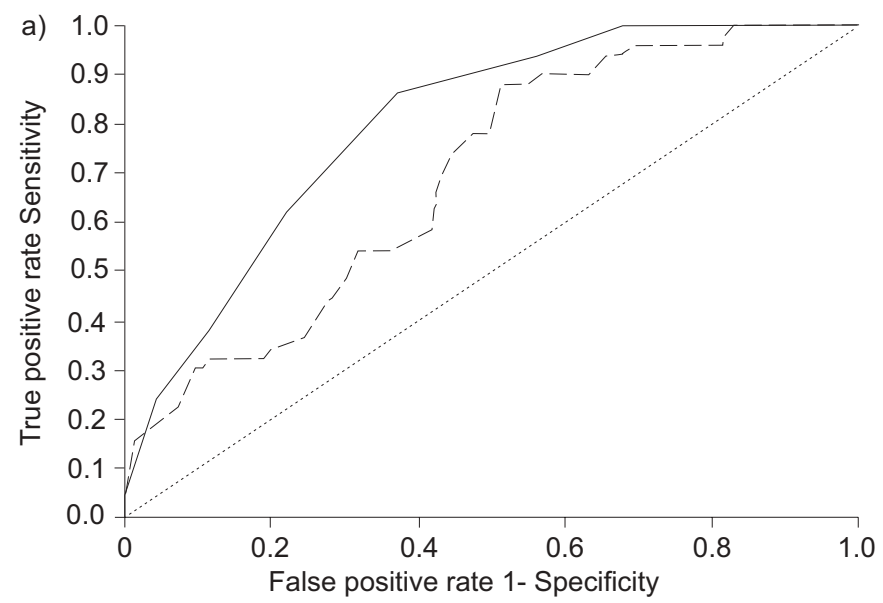

have better survival over time than males. Secondly, the BODE index predicts all-cause and respiratory mortality as well in females as in males.

In population-based studies, females live longer than males [30-32]. Recent epidemiological studies suggest an increased mortality rate in females with COPD $[33,34]$. However, there are very few clinical studies attempting to determine sex related differences in COPD survival adjusting for variables known to predict outcome. Four previous studies on highly selected patients with chronic respiratory failure and hypoxaemia have specifically addressed mortality differences between males and females. Three studies [16-18] indicated that females with COPD have a better prognosis than males, whereas one concluded the opposite [19]. МіуАмото et al. [16] studied 9,759 patients with COPD, tuberculosis sequelae or chronic interstitial pneumonia receiving long-term oxygen therapy (LTOT) and reported a better survival for females than males. CROCKETT et al. [17] studied a population of 505 COPD patients (256 females) also receiving LTOT and confirmed the previous findings. CROCKETT et al. [17] also reported that the prognostic factors for females (age, FEV1, BMI and comorbidities) were different from those of males (only BMI). Recently, FRANKLIN et al. [18] followed 5,689 COPD patients $(2,894$ females) on LTOT and, after adjusting by age, also found a better survival in females. Interestingly, FRANKLIN et al. [18] noted that the incidence and prevalence for LTOT increased more rapidly in females than males. All of these reports supported a better survival in females than in males with severe COPD. In contrast, MACHADO et al. [19] assessed 435 patients (184 females) with severe COPD receiving LTOT and followed them over time. Surprisingly, the risk of death, whether adjusted by age, smoking history, arterial oxygen tension, FEV1 and BMI, was higher in females than in males. The current results support a better survival of females compared to males with similar baseline severity of airflow obstruction or BODE.

There are important differences between the current and previous studies. First, while the previous studies included

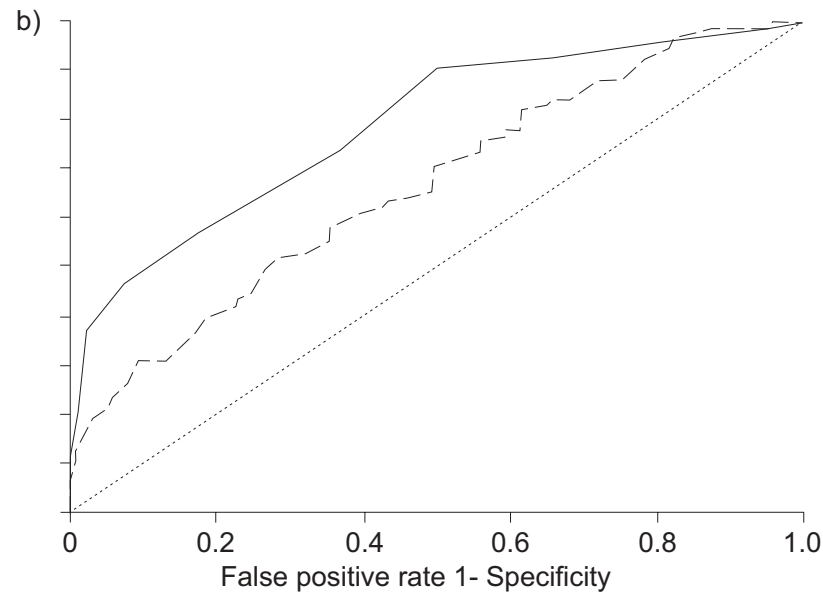

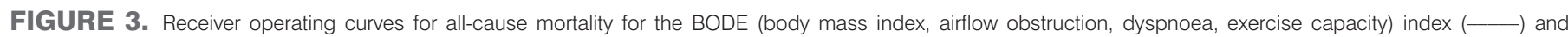

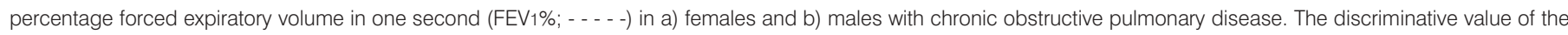

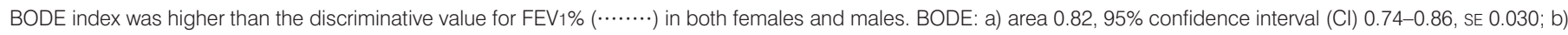
area $0.80,95 \% \mathrm{Cl} 0.73-0.84$, SE 0.029. FEV1: a) area 0.69, 95\% Cl 0.62-0.77, SE 0.038; b) area 0.66, 95\% Cl 0.60-0.73, SE 0.034. 
patients with severe disease and chronic respiratory failure requiring LTOT, the current study is based on a well phenotyped population of patients with a wide range of COPD severity. The majority of patients included in the current study had either mild or moderate COPD (stage I or II in the GOLD classification) and were in Q1 and Q2 of the BODE index. Secondly, previous studies adjusted the results by some prognostic factors but not by the best predictor of mortality in COPD, i.e. the BODE index [22].

In the current study, males were slightly older, had a longer smoking history and a higher comorbidity score than females; all factors that may play a role in the survival difference between males and females. However, the difference in mortality persisted after adjusting for these factors (tables 4 and 5), which suggests the presence of other reasons not detected by the Charlson comorbidity index. This suggests a need to develop a better index that can more precisely capture the comorbidities of importance in patients with COPD. Although the impact of comorbidities in the clinical course of COPD was described almost 10 yrs ago [35], it is only now that it has begun to receive specific attention [36]. In the present study, comorbidities seemed to impact only in all-cause mortality in males (tables 4 and 5). Surprisingly, when respiratory mortality was compared by BODE quartiles, a higher mortality was found in males than in females only in the most severe quartile. This is an important finding that reproduces those reported by CELLI et al. [22] and INCALZI et al. [35], which suggests that the course of COPD per se, may be similar in females and males as the COPD progresses and that the differences in overall survival in males with more severe COPD could possibly be due to added comorbidity. This could also explain the differences in all-cause mortality between both sexes. From the present study it is difficult to determine exactly if the type of comorbidity is the same for males and females because the overall Charlson comorbidity score, although higher in males, failed to reach statistical significance. It could be speculated that the increased mortality in males is due to a higher prevalence of cardiovascular disease and lung cancer in this sex, but this remains to be explored.

The multidimensional BODE index [22] was developed and validated in a cohort of patients with COPD that consisted primarily of males (95\%). BODE was a better predictor of outcome than the GOLD stages in two different studies [37, 38]. The current study expands these observations showing that the BODE index predicts survival in females as well as in males and that for both sexes the BODE index is a better predictor than $\mathrm{FEV} 1 \%$. The multivariate analysis showed that BODE index is an excellent predictor of all-cause and respiratory mortality for females and males. Interestingly, it has been previously reported that the relative weight of each individual component of the BODE index differs between males and females [39]. However, the composite index prognosticates with similar power in both sexes. This finding makes the BODE index very useful when comparing sex-related outcomes because it provides a global comprehensive overview not provided by the individual domains. The current data supports the usefulness of the BODE index as a tool to assess the multidimensional expression of the disease irrespective of sex.
The current findings have some clinical implications in the management of females with COPD. Given the better survival for females with the higher BODE scores (7-10), interventions such as lung volume reduction surgery or lung transplantation could be timed differently. For example, if a COPD patient in BODE Q4 is evaluated for lung transplant, the evaluating team should be aware that the 3-yr survival time for females is $\sim 50 \%$ while only $20 \%$ for males. Likewise, a more aggressive detection and treatment of comorbidities is suggested in males, as they are likely to be the cause of death in this sex.

There were some limitations to this study. First, the current study patients were enrolled in pulmonary clinics in Europe, Latin America and the USA; therefore, the findings may not be totally applicable to the entire worldwide COPD population. However, this study represents the largest study of well phenotyped females with COPD using the most important prognostic factors for the disease. Secondly, although the authors were careful to match male and female patients enrolled during the same study period, one cannot be entirely sure that differences in mortality are not due to treatment differences. However, none of the currently available treatments for the disease have shown to be sex sensitive [40]. Thirdly, the exact proportion of the causes of death may not be accurate since it was obtained from review of the medical records or death certificates. This is a known limitation of many COPD survival studies [41]. However, the primary outcome of the present study was to investigate sex differences in all-cause mortality, a very hard end-point. Fourthly, the present authors acknowledge the important impact that exacerbations have in mortality of COPD patients. Unfortunately, the authors did not have precise information in some study sites, thus preventing a robust analysis of the data. Finally, depression and anxiety were not evaluated in this cohort. However, these tend to be worse in females [42] and, if anything, would impact more on females than males.

In summary, the present study shows that all-cause and respiratory mortality are significantly lower in females than in males with similar chronic obstructive pulmonary disease severity. It also shows that the BODE (body mass index, airflow obstruction, dyspnoea, exercise capacity) index is as good a predictor of mortality in females with chronic obstructive pulmonary disease as in males with chronic obstructive pulmonary disease. Larger studies are needed to further investigate sex influence in the expression of chronic obstructive pulmonary disease.

\section{REFERENCES}

1 Langhammer A, Johnsen R, Holmen J, Gulsvik A, Bjermer L. Cigarette smoking gives more respiratory symptoms among women than among men. The NordTrondelag Health Study (HUNT). J Epidemiol Community Health 2000; 54: 917-922.

2 Langhammer A, Johnsen R, Gulsvik A, Holmen TL, Bjermer L. Sex differences in lung vulnerability to tobacco smoking. Eur Respir J 2003; 21: 1017-1023.

3 Chen Y, Horne SL, Dustman JA. Increased susceptibility to lung dysfunction in female smokers. Am Rev Respir Dis 1991; 143: 1224-1230. 
4 Prescott E, Bjerg AM, Andersen PK, Lange P, Vestbo J. Gender difference in smoking effects on lung function and risk of hospitalization for COPD: results from a Danish longitudinal population study. Eur Respir J 1997; 10: 822-827.

5 Ben-Zaken Cohen S, Paré PD, Paul Man SF, Sin DD. COPD and lung cancer in women: examining sex differences in cigarette smoke metabolism. Am J Respir Crit Care Med 2007; 176: 113-120.

6 Laurin C, Lavoie KL, Bacon SL, et al. Sex differences in the prevalence of psychiatric disorders and psychological distress in patients with COPD. Chest 2007; 132: 148-155.

7 Chavannes N, Huibers M, Schermer T, et al. Associations of depressive symptoms with gender, body mass index and dyspnea in primary care COPD patients. Fam Pract 2005; 22: 604-607.

8 Martinez F, Curtis J, Sciurba F, et al. Gender differences in severe pulmonary emphysema. Am J Respir Crit Care Med 2007; 176: 243-252.

9 Varkey AB. Chronic obstructive pulmonary disease in women: exploring gender differences. Curr Opin Pulm Med 2004; 10: 98-103.

10 de Torres JP, Casanova C, Hernandez C, Abreu J, AguirreJaime A, Celli BR. Gender and COPD in patients attending a pulmonary clinic. Chest 2005; 128: 2012-2016.

11 Tashkin DP, Altose MD, Bleecker ER, et al. The Lung Health Study: airway responsiveness to inhaled methacholine in smokers with mild to moderate airflow limitation. The Lung Health Study research Group. Am Rev Respir Dis 1992; 145: 301-310.

12 Ferrer M, Villasante C, Alonso J, et al. Interpretation of quality of life scores from the St George's Respiratory Questionnaire. Eur Respir J 2002; 19: 405-413.

13 de Torres JP, Casanova C, Hernandez C, et al. Gender associated differences in determinants of quality of life in patients with COPD: a case series study. Health Qual Life Outcomes 2006; 4: 72.

14 Oga T, Nishimura K, Tsukino M, Sato S, Hajiro T. Analysis of the factors related to mortality in chronic obstructive pulmonary disease. Role of exercise capacity and health status. Am J Respir Crit Care Med 2002; 167: 544-549.

15 Dransfield MT, Washko GR, Foreman MG, Estepar RSJ, Reilly J, Bailey WC. Gender differences in severity of CT emphysema in COPD. Chest 2007; 132: 464-470.

16 Miyamoto K, Aida A, Nishimura M, Aiba M, Kira S, Kawakami Y. Gender effect on prognosis of patients receiving long-term home oxygen therapy. The Respiratory Failure Research Group in Japan. Am J Respir Crit Care Med 1995; 152: 972-976.

17 Crockett AJ, Cranston JM, Moss JR, Alpers JH. Survival on long-term oxygen therapy in chronic airflow limitation: from evidence to outcomes in the routine clinical setting. Intern Med J 2001; 31: 448-454.

18 Franklin KA, Gustafson T, Ranstam J, Strom K. Survival and future need of long-term oxygen therapy for chronic obstructive pulmonary disease-gender differences. Respir Med 2007; 101: 1506-1511.

19 Machado MC, Krishnan JA, Buist SA, et al. Sex differences in survival of oxygen-dependent patients with chronic obstructive pulmonary disease. Am J Respir Crit Care Med 2006; 174: 524-529.
20 Celli BR, MacNee W, Agusti A, et al. Standards for the diagnosis and treatment of patients with COPD: a summary of the ATS/ERS position paper. Eur Respir J 2004; 23: 932-946.

21 Pauwels RA, Buist AS, Calverley PM, Jenkins CR, Hurd SS, GOLD Scientific Committee. Global strategy for the diagnosis, management and prevention of chronic obstructive pulmonary disease. NHLBI/WHO Global Initiative for Chronic Obstructive Lung Disease (GOLD) Workshop summary. Am J Respir Crit Care Med 2001; 163: 1256-1276.

22 Celli BR, Cote CG, Marin JM, et al. The body-mass index, airflow obstruction, dyspnea and exercise capacity index in COPD. N Engl J Med 2004; 350: 1005-1012.

23 Standardization of spirometry, 1994 update. American Thoracic Society. Am I Respir Crit Care Med 1995; 152: 1107-1136.

24 ATS Statement: Guidelines for the six-minute walk test. Am J Respir Crit Care Med 2002; 166: 111-117.

25 Mahler DA, Weinberg DH, Wells CK, Feinstein AR. The measurement of dyspnea: contents, inter-observer agreement, and physiologic correlates of two new clinical indexes. Chest 1984; 85: 751-758.

26 Charlson M, Szatrowski TP, Peterson J, Gold J. Validation of a combined comorbidity index. J Clin Epidemiol 1994; 47: 1245-1251.

27 Casanova C, Cote C, de Torres JP, et al. Inspiratory-to-total lung capacity ratio predicts mortality in patients with chronic obstructive pulmonary disease. Am J Respir Crit Care Med 2005; 171: 591-597.

28 Jones PW, Quirk FH, Baveystock CM, Littlejohns P. A self complete measure for chronic airflow limitation: the St George's Respiratory Questionnaire. Am Rev Respir Dis 1992; 142: 1321-1327.

29 Jones PW. St. George's Respiratory Questionnaire: MCID. COPD 2005; 2: 75-79.

30 Mannino DM, Doherty DE, Sonia BA. Global Initiative on Obstructive Lung Disease (GOLD) classification of lung disease and mortality: findings from the Atherosclerosis Risk in Communities (AARIC) study. Respir Med 2006; 100: 115-122.

31 La salud de los hombres en la Región de las Américas. [Men's health in the Americas.] Pam Am J Public Heath 1998; 4: 362-366.

32 Goméz Redondo R. La mortalidad de la España actual. [Mortality in Spain at the present time.] Politica y Sociedad 1997; 26: 41-61.

33 Mannino DM. COPD: epidemiology, prevalence, morbidity and mortality, and disease heterogeneity. Chest 2002; 121: Suppl. 5, 121S-126S.

34 Mannino DM. Chronic obstructive pulmonary disease surveillance - United States, 1971-2000. Respir Care 2002; 47: 1184-1199.

35 Incalzi RA, Fuso L, De Rosa M. Co-morbidity contributes to predict mortality of patients with chronic obstructive pulmonary disease. Eur Respir J 1997; 10: 2794-2800.

36 Sin DD, Anthonisen NR, Soriano JB, Agusti AG. Mortality in COPD: role of comorbidities. Eur Respir J 2006; 28: 1245-1257.

37 Martinez FJ, Foster G, Curtis JL, et al. Predictors of mortality in patients with emphysema and severe airflow obstruction. Am J Respir Crit Care Med 2006; 173: 1326-1334.

38 Imfeld S, Bloch KE, Weder W, Russi EW. The BODE index after lung volume reduction correlates with survival in COPD. Chest 2006; 129: 835-836. 
39 de Torres JP, Casanova C, Montejo de Garcini A, AguirreJaime A, Celli BR. COPD heterogeneity: gender differences in the multidimensional BODE index. Int J Chron Obstruct Pulmon Dis 2007; 2: 151-155.

40 Vestbo J, Soriano JB, Anderson JA, et al. Gender does not influence the response to the combination of salmeterol and fluticasone propionate in COPD. Respir Med 2004; 98: 1045-1050.
41 Hansell A, Walk JA, Soriano JB. What do chronic obstructive pulmonary disease patients die from? A multiple cause coding analysis. Eur Respir J 2003; 22: 809-814.

42 Fan VS, Ramsey SD, Giardino ND, et al. National Emphysema Treatment Trial (NETT) Research Group. Sex, depression, and risk of hospitalization and mortality in chronic obstructive pulmonary disease. Arch Intern Med 2007; 167: 2345-2353. 